\title{
Dosage-Related Prebiotic Effects of Inulin in Formula-Fed Infants
}

\author{
Hanifah Oswari ${ }^{*}{ }^{\dagger}$, Ariani Dewi Widodo ${ }^{\dagger}$, Frieda Handayani ${ }^{\dagger}$, Mohammad Juffrie $^{\dagger,}{ }^{\ddagger}$, \\ Tonny Sundjaya ${ }^{\S}$, Jacques Bindels ${ }^{\Uparrow}$, and Badriul Hegar ${ }^{*, \dagger}$ \\ *Department of Child Health, Cipto Mangunkusumo Hospital, Faculty of Medicine, Universitas Indonesia, Jakarta, \\ ${ }^{+}$Research Task Force, Indonesian Pediatric Society (IDAI), Jakarta, ${ }^{\dagger}$ Department of Pediatrics, Faculty of Medicine, \\ Universitas Gadjah Mada, Yogyakarta, ${ }^{s}$ Danone Nutricia Early Life Nutrition R\&D, Jakarta, Indonesia, "Nutricia \\ Research, Danone Nutricia Early Life Nutrition, Singapore, Singapore
}

Purpose: The aim of this study was to identify the minimally meaningful dosage of inulin leading to a prebiotic effect in Indonesian infants.

Methods: In a randomized controlled double-blinded, parallel, 3-arm intervention study, 164 healthy formula-fed infants aged 3 to 5 months first obtained formula-A (without inulin) during a 4-week adaptation period. Subsequently, 142 subjects were subjected to a 4-week feeding period by administering either formula-A (no inulin), formula-B $(0.2 \mathrm{~g} / 100 \mathrm{~mL}$ inulin) or formula-C $(0.4 \mathrm{~g} / 100 \mathrm{~mL}$ inulin). The primary outcome parameter was \%-bifidobacteria in faecal samples determined using quantitative polymerase chain reaction analyses. Secondary outcome parameters were faecal \%-lactobacilli, $\mathrm{pH}$ and stool frequency, and consistency. Growth and tolerance/adverse effects were recorded as safety parameters.

Results: Typical \%-bifidobacteria and \%-lactobacilli at the end of the adaptation period in the study population were $14 \%$ and $2 \%$, respectively. For faecal $\mathrm{pH}$, significant differences between formula groups $\mathrm{A}$ vs. $\mathrm{C}$ and $\mathrm{A}$ vs. $\mathrm{B}$ were found at the end of the intervention period. Testing for differences in faecal \%-bifidobacteria and \%-lactobacilli between groups was hampered by non-normal data set distributions; no statistically significant differences were obtained. Comparisons within groups revealed that only in formula group $\mathrm{C}$, all the three relevant parameters exhibited a significant effect with an increase in faecal \%-bifidobacteria and \%-lactobacilli and a decrease in $\mathrm{pH}$. Conclusion: A consistent prebiotic effect along with a decrease in $\mathrm{pH}$ and increase in \%-bifidobacteria and \%-lactobacilli was found only in the group administered $0.4 \mathrm{~g}$ inulin/100 $\mathrm{mL}$.

Key Words: Infant formula, Prebiotics, Inulin, Gastrointestinal microbiome

Received : May 30, 2018, Revised: August 30, 2018, Accepted : September 12, 2018

Corresponding author: Hanifah Oswari, Department of Child Health, Faculty of Medicine, Cipto Mangunkusumo Hospital, Faculty of Medicine, Universitas Indonesia, JI Diponegoro 71, Jakarta 10430, Indonesia. Tel: +62-21-390-7742, Fax: +62-21-390-7743, E-mail: hoswari@gmail.com

Copyright (c) 2019 by The Korean Society of Pediatric Gastroenterology, Hepatology and Nutrition

This is an open-access article distributed under the terms of the Creative Commons Attribution Non-Commercial License (http://creativecommons.org/licenses/by-nc/4.0/) which permits unrestricted non-commercial use, distribution, and reproduction in any medium, provided the original work is properly cited. 


\section{INTRODUCTION}

Dietary prebiotics are defined as selectively fermented ingredients that result in specific changes in the composition and/or activity of the gastrointestinal microbiota, thus conferring benefit(s) upon host health [1]. In infants, prebiotic effects include stimulation of bifidobacterial growth and a decrease in faecal $\mathrm{pH}$, representing both composition and activity of the microbiota. Whether these changes reflect immediate or long-term health benefits to the host is still a subject of research. Beneficial effects on the immune system are reported based on the reduction in the infections and the risk for atopic disease [2], but it remains unclear whether these effects are general features, or are specific for individual prebiotics or mixtures.

Several studies in infants have confirmed bifidogenic and related effects of various prebiotics like the galacto-oligosaccharides/long-chain fructo-oligosaccharides (GOS/lcFOS) mixture [3], short-chain fructo-oligosaccharides (scFOS) or oligofructose [4], specific mixtures of scFOS and lcFOS or inulin [5], GOS alone [6], and GOS/ polydextrose mixture [7]. In the reported studies, dosages of $0.4 \mathrm{mg} / 100 \mathrm{~mL}$ [3-5,7] and $0.5 \mathrm{mg} / 100 \mathrm{~mL}[6]$ of prebiotics were reported to be effective. A recent review [8] lists only 3 studies investigating the prebiotic/bifidogenic effect of inulin in infants [9-13], and all used traditional culturing methods. Native inulin from chicory is a mixture of oligomers and polymers with a degree of polymerization (DP) ranging from 2 to 65 and average DP of 10. Inulin can be considered as a suitable prebiotic because apart from fermentation in the proximal colon of molecules with DP $<10$, it also provides larger structures allowing fermentation to take place over a wider stretch of the colon $[8,13,14]$. The gradual fermentation of inulin also translates into reduced incidence of symptoms like flatulence and bloating. In healthy young adults, doses of up to $10 \mathrm{~g}$ inulin/day were well tolerated compared to dosages of up to $5 \mathrm{~g}$ oligofructose/day [15].

Information about the gut microbiota in Indonesian infants is limited, and studies using molecular probe techniques are scarce $[16,17]$. Studies in Malaysia and Korea on employment of inulin at dosages as low as 1.25 and $1.5 \mathrm{~g}$ /day have already revealed a bifidogenic effect in infants $[9,10,12]$. We investigated the effect of the addition of native inulin to an infant formula at different dosages $(0.2$ and $0.4 \mathrm{~g} / 100 \mathrm{~mL}$, equivalent to 1.6 and $3.2 \mathrm{~g} /$ day with $800 \mathrm{~mL}$ formula intake).

\section{MATERIALS AND METHODS}

A randomized double-blinded controlled clinical study was carried out in three community health centers (Puskesmas) in Jakarta districts, Senen, Kemayoran, and Setiabudi. Infants, fully formula-fed for at least 28 days, aged 91 to 150 days with weight and body length within \pm 2 standard deviation (SD) of World Health Organization (WHO) growth charts, were considered eligible for the study. Excluded were the infants with birth weight $<2,000$ $\mathrm{g}$, disorders requiring a special diet, use of systemic antibiotics or anti-mycotics medication within 14 days prior to study entry, significant congenital abnormality, uncertainty about the willingness or ability of the parents to comply with the protocol requirements, and participation in any other potentially conflicting studies.

The study was conducted in accordance with Good Clinical Practice and the Indonesian National Agency for Drug and Food Control guidance. The protocol and later amendments were approved by the Medical Research Ethics Committee of the University of Indonesia/Cipto Mangunkusumo Hospital, Jakarta, Indonesia (No. 457/PT02.FK/ ETIK/2011). The present study was registered in the ClinicalTrials.gov PRS database as NCT01515644.

Study products were: (A) powder-based infant formula without inulin, (B) formula with $0.2 \mathrm{~g}$ inulin/100 mL, and (C) formula with $0.4 \mathrm{~g}$ inulin/100 $\mathrm{mL}$. Composition and characteristics of the three products were exceedingly similar. The study included a 4-week adaptation phase to "wash out" any prebiotic effect of the existing formula. The second 4-week period included the product intervention 
with a formula containing $0,0.2$, and $0.4 \mathrm{~g}$ inulin/ 100 $\mathrm{mL}$. The formula used by all the subjects during the adaptation period was identical to the formula used by study group A, but was labeled and coded differently. Every week until 2 weeks after the end of the intervention, a contact session with the parents either by visit or by phone was conducted. Subjects who did not consume study product for a period $>2$ days consecutively, or with intake of study product $<500 \mathrm{~mL}$ per day for 7 days were withdrawn from the study. The primary outcome parameter was the difference between the percentage of bifidobacteria of total bacteria in the stool before and at the end of the intervention period. Secondary outcomes included \%-lactobacilli, $\mathrm{pH}$, and stool consistency and safety and tolerability of the investigational products. Parents had to fill in a daily diary on intake of study product (amount, frequency), possible other food intake, occurrences of discomfort (diarrhoea, constipation, vomiting, gassing, crying, sensation of illness, loss of appetite, infected eye, skin rashes, etc.) and changes in stool consistency using the Bristol Stool Form Scale [18]. Stool samples obtained before and at the end of the intervention period were collected in a sterile container and transported within 60 minutes to the study site or the prodia central laboratory in a cold storage container, and then stored at $-80^{\circ} \mathrm{C}$ until further analysis.

Body weight, length and head circumference of the infants were measured biweekly. Weight-for-age and length-for-age z-scores were based on the WHO growth charts [19]. DNA extraction for polymerase chain reaction (PCR) analysis was performed from approximately $100 \mathrm{mg}$ faecal samples using the Phenol/Chloroform method. Real-time quantitative PCR was performed using an ABI 7500 Fast Sequence Detection System (software version 2.0; Applied-Biosystems, Foster City, CA, USA) to measure total bacteria, bifidobacteria and lactobacilli levels in the stool. Primers used in this study were designed based on 16S rRNA gene sequences (The European Molecular Biology Laboratory database) obtained from Invitrogen (Carlsbad, CA, USA) and Life Technologies NZ Ltd (Auckland, New Zealand) aligned with the program CLUSTAL W (http://www. clustal.org). Amplification and detection were carried out as described before [16]. To eliminate variations in absolute amounts of bifidobacteria and lactobacilli due to faecal water content, we expressed the level of bifidobacteria and lactobacilli as a percentage of total bacteria quantified from the same sample [20].

Based on a two-sample $t$-test for mean difference, a minimal sample size of 49 subjects per group was calculated to allow a power of 0.8 at the expected mean difference of $10 \%$ and SD of $15 \%$ with an alpha of 0.0167 and two-sided testing. The expected mean difference and SD were inferred from earlier studies [21-23]. We used a conservative value for alpha because of the 3-group design. Anticipating a drop-out rate of $15 \%$, a recruitment target size of $n=56$ per group was considered adequate. Six different randomization letter codes were used, 2 letters for each product. The identity of the codes was blinded to the investigators and site staff. Randomisation was done based on subject sequence number per individual for each site; we used computer-generated random number lists and a block size of 6 . Unblinding was done after the database was locked.

The analysis was conducted using SPSS ver. 13.0 for Windows (SPSS Inc., Chicago, IL, USA). All data were checked for normal distribution according to Kolmogorov-Smirnov procedure with Lilliefors significance correction and the Shapiro-Wilk test. For the analysis of parametric data, the study outcome was evaluated using one-way ANOVA analysis; Kruskal-Wallis analysis was used for non-parametric data.

\section{RESULTS}

Typically, 180 healthy fully formula-fed infants were selected for recruitment from the records of three community centers in Jakarta. The further flow of the study is depicted in Fig. 1. Table 1 presents the age and anthropometric characteristics of the 142 subjects at the time of study entry after completion of the adaptation phase. The baseline charac- 


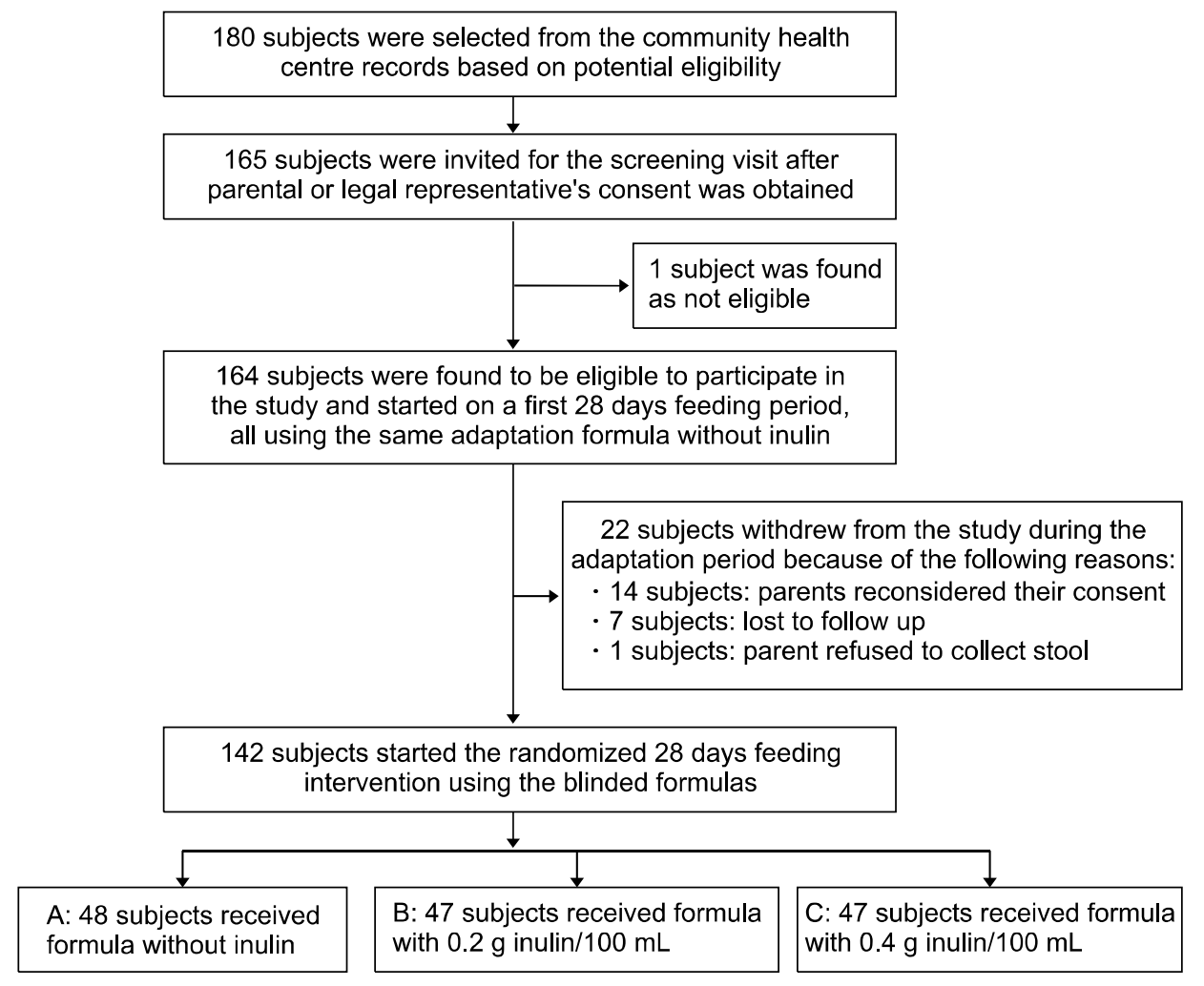

Fig. 1. Flowchart of the study.

Table 1. Characteristics of the Subjects at Study Entry, Which Successfully Completed the Adaptation Period

\begin{tabular}{lccc}
\hline \multicolumn{1}{c}{ Characteristic } & Group A $(\mathrm{n}=48)$ & Group B $(\mathrm{n}=47)$ & Group C $(\mathrm{n}=47)$ \\
\hline Age $(\mathrm{d})$ & $108(97 / 120)$ & $112 \pm 14$ & $105(96 / 118)$ \\
Weight $(\mathrm{g})$ & $5,850(5,400 / 6,300)$ & $5,910 \pm 620$ & $5,800(5,500 / 6,600)$ \\
Height $(\mathrm{cm})$ & $61.7 \pm 2.0$ & $61.5 \pm 2.1$ & $61.8 \pm 2.4$ \\
WAZ & $-0.88 \pm 0.78$ & $-0.95 \pm 0.84$ & $-0.69 \pm 0.87$ \\
HAZ & $-0.23(-0.93 /+0.31)$ & $-0.46 \pm 0.82$ & $-0.19 \pm 0.93$ \\
Sex, male/female & $21 / 27$ & $26 / 21$ & $22 / 25$ \\
Delivery mode, vaginal/C-section & $38 / 10$ & $34 / 13$ & $32 / 15$ \\
Preterm labor $(\mathrm{y} / \mathrm{n})$ & $6 / 42$ & $3 / 44$ & $6 / 41$ \\
Birth weight $(\mathrm{g})$ & $3,100(2,860 / 3,290)$ & $3,110 \pm 470$ & $3,100 \pm 450$ \\
Mother's age $(\mathrm{y})$ & $29.3 \pm 7.2$ & $31.8 \pm 6.3$ & $30.2 \pm 7.1$ \\
Child sequence & $2(1 / 2)$ & $2(1 / 4)$ & $2(1 / 3)$ \\
\hline
\end{tabular}

Values are presented as median (quartile value P25/P75) or mean \pm standard deviation.

Group A: control, group B: $0.2 \mathrm{~g}$ inulin/ $100 \mathrm{~mL}$, group C: $0.4 \mathrm{~g}$ inulin/100 mL.

WAZ: weight/age z-score, HAZ: height/age z-score.

teristics of the three treatment groups were well matched as to gender, delivery mode, birth weight, mother's age, and child sequence.

Baseline values of bifidobacteria and lactobacilli expressed as a percentage of total bacteria in the stool (typical values for the total population: 14 and $2 \%$, respectively), $\mathrm{pH}$ and stool consistency were comparable between the treatment groups before the initiation of the intervention phase. Most of the data were non-normally distributed. No statistically 
significant differences in the levels of \%-bifidobacteria and \%-lactobacilli were found between the treatment groups at the start and at the end of the intervention phase. Comparison within groups revealed that upon intervention only in the formula group with inulin dosage of $0.4 \mathrm{~g} / 100 \mathrm{~mL}$, a statistically significant increase from baseline in \%-bifidobacteria $(p=0.00)$ was observed. The levels of \%-lactobacilli showed a significant increase in all the three groups upon intervention $(p \leq 0.02)$. No differences were found in the stool $\mathrm{pH}$ between the treatment groups before the start of the intervention phase. At the end of the intervention, a significant difference in the stool $\mathrm{pH}$ between the treatment groups was observed. Within the control group, a statistically significant increase $(p=0.03)$ was observed, while in both the intervention groups we found a statistically significant decrease ( $p=0.04$ and 0.00 , respectively). The median number of defecations of the infants in the feeding groups at the start and end of intervention ranged from 1.1 to 1.35 per day and all inter- quartile ranges were between 1.0 and 2.0 stools/day. We observed no differences amongst or within the feeding groups. Typically, $77 \%$ of the infants in our study had soft stools (grading 6 according to the Bristol stool chart) and no significant differences were found in stool consistency between and within the treatment groups (Table 2).

Formula consumption during the intervention phase of the study was similar between the three groups. Median consumption was $991 \mathrm{~mL} /$ day for the combined groups and the interquartile range was 819 to $1,169 \mathrm{~mL} /$ day. There were no statistically significant differences between weight/age z-score and height/age z-score on any of the measuring visits between and within the groups. Infants from all the three groups tracked along the growth curve normally. There were no differences in clinical symptoms of diarrhoea, vomiting, crying, constipation, and flatulence or other potential adverse effects on day- 1 and on day-28 of intervention between or within the treatment groups. No differences in con-

Table 2. Primary and Secondary Outcome Parameters at the End of the Adaptation Period (Start) and at Day 28 of the Intervention Phase (End)

\begin{tabular}{|c|c|c|c|c|}
\hline $\begin{array}{l}\text { Outcome } \\
\text { parameter }\end{array}$ & Group A $(n=48)$ & Group B $(n=47)$ & Group C $(n=47)$ & $p$-value \\
\hline \multicolumn{5}{|c|}{ Bifidobacteria (\%) } \\
\hline Start & $16.8(8.8 / 32.4)$ & $17.1(7.1 / 31.0)$ & $12.1(7.3 / 22.5)$ & 0.5 \\
\hline End & $19.8(13.7 / 36.6)$ & $18.4(10.3 / 32.9)$ & $24.7(13.2 / 40.5)$ & 0.3 \\
\hline Difference & $+4.8(-2.2$ to +11.8$)$ & $+1.2(-4.7$ to +7.1$)$ & $+9.9^{*}(+4.7$ to +15.1$)$ & $0.13^{\dagger}$ \\
\hline \multicolumn{5}{|c|}{ Lactobacilli (\%) } \\
\hline Start & $1.7(0.5 / 3.8)$ & $2.6(0.7 / 7.7)$ & $2.2(1.0 / 4.7)$ & 0.3 \\
\hline End & $2.9(1.4 / 7.6)$ & $3.7(1.7 / 7.6)$ & $4.4(2.1 / 8.6)$ & 0.3 \\
\hline Difference & $+1.0^{*}(-0.0 /+3.3)$ & $+0.7^{*}(-0.9 /+4.7)$ & $+1.2 *(-0.1 /+3.9)$ & 0.8 \\
\hline \multicolumn{5}{|l|}{ Faecal pH } \\
\hline Start & $5.61(5.17 / 6.31)$ & $5.81(5.41 / 6.32)$ & $5.75(5.24 / 6.52)$ & 0.5 \\
\hline End & $5.96(5.49 / 6.60)$ & $5.44(5.09 / 6.18)$ & $5.30(4.97 / 5.99)$ & 0.000 \\
\hline Difference & $+0.27^{*}(+0.05$ to +0.49$)$ & $-0.23 *(-0.50$ to -0.03$)$ & $-0.41^{*}(-0.64$ to -0.17$)$ & $0.000^{\dagger}$ \\
\hline \multicolumn{5}{|c|}{ Stool consistency (Bristol scale: 1-7) } \\
\hline Start & $6(6 / 6)$ & $6(5 / 6)$ & $6(6 / 6)$ & 0.4 \\
\hline End & $6(5 / 6)$ & $6(6 / 6)$ & $6(6 / 6)$ & 0.6 \\
\hline
\end{tabular}

Values are presented as median (quartile value P25/P75) or mean (95\% confidence interval).

Group A: control, group B: $0.2 \mathrm{~g}$ inulin/100 mL, group C: $0.4 \mathrm{~g}$ inulin/100 mL.

Statistical analysis between the groups was done using Kruskal-Wallis test, except indicated otherwise. Statistical analysis within groups on the differences between end and the start was done using Wilcoxon test except for the differences in bifidobacteria (\%) and faecal $\mathrm{pH}$, where $t$-test was used.

${ }^{*}$ Difference statistically significant $(p<0.05) .{ }^{\dagger}$ Analyzed using one-way ANOVA. 
comitant medication and compliance were observed.

\section{DISCUSSION}

The first study on the evaluation whether the addition of prebiotic oligosaccharides to term infant formula imparts a bifidogenic effect in a dose-dependent manner was reported in 2002 [3]. This was followed by several other studies using numerous substrates at dosages ranging from 0.15 to $0.8 \mathrm{~g} / 100$ $\mathrm{mL}$ [4-12]. The issue that the effects observed at the level of the infant's gut ecosystem are validated markers for clinical benefits or not is still under debate [2]. Nevertheless, the World Allergy Organization guideline panel recently gave a conditional recommendation for prebiotic supplementation for the prevention of allergy in non-exclusively breastfed infants [24]. The European Society for Paediatric Gastroenterology, Hepatology and Nutrition Committee on Nutrition concluded that prebiotic supplementation of infant formula has the potential to decrease stool $\mathrm{pH}$, increase stool frequency, soften stools, and increase stool colony counts of bifidobacteria and lactobacilli [2]. The current study is the first study to demonstrate the effect of native inulin supplementation on the microbiota using molecular biology-based methods.

In our study, we found that the proportion of bifidobacteria remained fairly unaltered in the $0.2 \mathrm{~g}$ inulin/100 $\mathrm{mL}$ formula feeding group with a median intake of $2 \mathrm{~g} /$ day, which contrasted the results from studies performed in Korea and Malaysia, demonstrating significant increases of bifidobacteria were reported at inulin dosages of 1.5 and $1.25 \mathrm{~g} /$ day, respectively $[9,10]$. Both the studies analyzed the infant gut microbiota using traditional culturing methods where only live bacteria can be assessed. In a report on parallel analyses of the samples from a study in infants performed by traditional culturing methods and using a molecular biologic technique (fluorescent in situ hybridization, FISH), the effect of either analyzing only culturable or total bifidobacterial has been elegantly demonstrated [25]. Both the methods revealed an increase in bifidobac- teria in the prebiotic group compared to control, but the effect was much more pronounced upon observing the graph from the traditional culturing analyses. Thus, it may seem that the traditional culturing method is more sensitive. However, this statement is incorrect because many strains cannot be cultured and most media used for quantification are nonspecific [20]. Likely, it is apparent as for why we could not observe the effects in the $0.2 \mathrm{~g}$ inulin/100 $\mathrm{mL}$ supplementation group using molecular detection, compared to other reported findings at similar or even lower inulin dosages $[9,10]$.

Most of the referenced intervention studies investigating the effect of formulas supplemented with at least $0.2 \mathrm{~g} / 100 \mathrm{~mL}$ prebiotics on the microbiota in term infants using molecular detection methods recruited infants at an early time after birth $[3-5,7,26,27]$, whereas 4 studies recruited infants after the age of 1 month with an already established microbiota $[6,21,27,28]$. Interestingly, in 2 of those 4 studies $[27,28]$, the effect on bifidogenicity was weak and not statistically significant and it was discussed that prebiotics may have a greater impact on infant fecal bacterial populations in younger infants than in older infants [28]. The reported results are in accordance with our finding that we did not observe a convincing effect in the $0.2 \mathrm{~g}$ inulin/100mL dosage group in infants recruited at age of 3 and 4 months.

We did not record the full feeding history before recruitment and only limited the survey to ascertain that the subjects were already on 4 weeks of full formula feeding before being allowed to participate. The Indonesian Health Profile data from the "Data and Information Center" (Pusdatin) by the Indonesian ministry of health revealed that in the DKI Jakarta province where our study sites are located, $72 \%$ of the newborn babies were initially introduced to breastmilk [29]. As we have no reason to assume that these figures would clearly be different in our specific study population, it is reasonable to assume that most of the infants in our study population were initially breastfed, although only for a limited period. The period of 4 weeks for both the wash-out and the intervention part of our study was inferred from 
adult intervention studies with inulin, where typical effects were studied after 2 weeks [30,31] for each wash-out and intervention phase. Several comparable studies in infants applied a 2 to 6 weeks wash-out and/or intervention periods $[6,21,22]$ and our results (significant changes in $\mathrm{pH}$ and bifidobacterial) during 4 weeks intervention period demonstrate that this period is adequate for studies in infants.

An increase in lactobacilli due to supplementation of the prebiotic mixture GOS/lcFOS in infant formula was first reported using traditional culturing methods [3] and later confirmed using molecular methods [21]. In the other six relevant studies [4-6,9-11], a few demonstrated no effects [4,9], others a statistically non-significant trend $[5,6]$ and a couple reported a significant increase using culturing methods $[10,11]$. We found a significant increase within all the three feeding groups and conclude that the effect of the various prebiotic oligosaccharides on lactobacilli is still inconclusive.

The most obvious indicator in our study on the effect of the addition of prebiotics to infant formula in Indonesia was the decrease in stool $\mathrm{pH}$ suggesting an effect on colonic metabolic activity. We observed this decrease in the 0.2 and $0.4 \mathrm{~g}$ inulin/ $100 \mathrm{~mL}$ formula groups, while in the control formula, an increase was observed. These findings are similar to an earlier study where the decrease in $\mathrm{pH}$ was significant, but the increase in \%-bifidobacteria analyzed using FISH did not reach statistical significance when compared to the control group [26].

Most of the studies on prebiotic supplementation of infant formula reported no significant effects on stool frequency, which is in line with our findings [3,5,6,9-11]. For stool consistency, a dose-dependent effect towards softer stools was reported in three studies [3,5,27]. Nearly all the infants in our study had soft stools (Bristol score 5-6) with no differences between or within the groups. The only sign towards a stool softening effect was that two infants in the control group were recorded with hard stools (Bristol score 1-3) at the end of the intervention, while this figure was zero for both the inulin groups. A further softening of the already soft stools (Bristol score 6) of the infants in our study may not have been advantageous.

The non-normal distribution of most of the outcome parameter data represented a major challenge. We already decided not to report any microbiota results as absolute count but rather represent them as a proportion of total bacteria [20], but this did not prevent the non-normal distribution. Attempts applying log- or other types of transformations were unsuccessful as contrast was lost. Alternative modeling approaches for our type of non-normally distributed data are sparse and we did not pursue this route. The design to include a 4-week adaptation phase turned out to be the strength of our study, as all the subject dropouts occurred in the period before the infants were subjected to the blinded randomized intervention phase. Based on our findings on stool consistency, we question whether applying the Bristol stool scores is suitable for our type of population as the potential contrast in the softer stool range may be too small.

In conclusion, we found a significant increase in faecal \%-bifidobacteria upon the dietary intervention with $0.4 \mathrm{~g}$ inulin/100 $\mathrm{mL}$ and not in the control or lower dosage group. This result, combined with the significant decrease in $\mathrm{pH}$ in both the inulin groups contrasted with a significant increase in the control group together with the statistically significant difference between the groups on $\mathrm{pH}$, provides sufficient support to conclude that only the investigated infant formula with $0.4 \mathrm{~g}$ inulin/100 mL can be considered as prebiotic based on perceived beneficial effects on relative amounts of bifidobacteria and stool $\mathrm{pH}$.

\section{ACKNOWLEDGEMENTS}

The authors are extremely grateful to the parents and caretakers of the infants for their participation in the study. Eleonora Mitaning Christy MD, Samuel Stemi MD, Ifan Citra MD, the staff of the local health care centers (Posyandu, Puskesmas), are greatly acknowledged. The practical execution, monitoring, 
and reporting of this study was supported by Prodia, the CRO in a highly professional way. We also acknowledge Dr. Sutantik Endang Wasih Kasunjatan, M.Epid. for excellent statistical analyses and supervision. This study was sponsored by PT Sari Husada Generasi Mahardhika, but the sponsorship had no influence on the outcomes of the study. TS and JB are employees of Danone-Nutricia ELN RED. None of the authors have any personal or financial conflict of interest to declare.

\section{REFERENCES}

1. Roberfroid M, Gibson GR, Hoyles L, McCartney AL, Rastall R, Rowland I, et al. Prebiotic effects: metabolic and health benefits. Br J Nutr 2010;104 Suppl 2:S1-63.

2. Braegger C, Chmielewska A, Decsi T, Kolacek S, Mihatsch W, Moreno L, et al. Supplementation of infant formula with probiotics and/or prebiotics: a systematic review and comment by the ESPGHAN committee on nutrition. J Pediatr Gastroenterol Nutr 2011;52:238-50.

3. Moro G, Minoli I, Mosca M, Fanaro S, Jelinek J, Stahl $\mathrm{B}$, et al. Dosage-related bifidogenic effects of galactoand fructooligosaccharides in formula-fed term infants. J Pediatr Gastroenterol Nutr 2002;34:291-5.

4. Paineau D, Respondek F, Menet V, Sauvage R, Bornet F, Wagner A. Effects of short-chain fructooligosaccharides on faecal bifidobacteria and specific immune response in formula-fed term infants: a randomized, double-blind, placebo-controlled trial. J Nutr Sci Vitaminol (Tokyo) 2014;60:167-75.

5. Veereman-Wauters G, Staelens S, Van de Broek H, Plaskie K, Wesling F, Roger LC, et al. Physiological and bifidogenic effects of prebiotic supplements in infant formulae. J Pediatr Gastroenterol Nutr 2011;52:763-71.

6. Fanaro S, Marten B, Bagna R, Vigi V, Fabris C, Peña-Quintana L, et al. Galacto-oligosaccharides are bifidogenic and safe at weaning: a double-blind randomized multicenter study. J Pediatr Gastroenterol Nutr 2009;48:82-8.

7. Scalabrin DM, Mitmesser SH, Welling GW, Harris CL, Marunycz JD, Walker DC, et al. New prebiotic blend of polydextrose and galacto-oligosaccharides has a bifidogenic effect in young infants. J Pediatr Gastroenterol Nutr 2012;54:343-52.

8. Firmansyah A, Chongviriyaphan N, Dillon DH, Khan NC, Morita T, Tontisirin K, et al. Fructans in the first 1000 days of life and beyond, and for pregnancy. Asia Pac J Clin Nutr 2016;25:652-75.
9. Yap WKW, Mohamed S, Husni Jamal M, Diederick M, Manap YA. Changes in infants faecal characteristics and microbiota by inulin supplementation. J Clin Biochem Nutr 2008;43:159-66.

10. Kim SH, Lee DH, Meyer D. Supplementation of baby formula with native inulin has a prebiotic effect in formula-fed babies. Asia Pac J Clin Nutr 2007;16:172-7.

11. Lugonja NM, Martinov OB, Rasovic MR, Spasic SD, Gojgic GDj, Vrvic MM. A comparative investigation of an in vitro and clinical test of the bifidogenic effect of an infant formula. J Clin Biochem Nutr 2010;47: 208-16.

12. Yap KW, Mohamed S, Yazid AM, Maznah I, Meyer DM. Dose-response effects of inulin on the faecal short-chain fatty acids content and mineral absorption of formulafed infants. Nutr Food Sci 2005;35:208-19.

13. Loo JV. Inulin-type fructans as prebiotics. In: Gibson GR, Rastall RA, eds. Prebiotics: development and application. Chichester: John Wiley \& Sons, 2006: 57-100.

14. van de Wiele T, Boon N, Possemiers S, Jacobs H, Verstraete W. Inulin-type fructans of longer degree of polymerization exert more pronounced in vitro prebiotic effects. J Appl Microbiol 2007;102:452-60.

15. Bonnema AL, Kolberg LW, Thomas W, Slavin JL. Gastrointestinal tolerance of chicory inulin products. J Am Diet Assoc 2010;110:865-8.

16. Oswari H, Prayitno L, Dwipoerwantoro PG, Firmansyah A, Makrides M, Lawley B, et al. Comparison of stool microbiota compositions, stool alpha1-antitrypsin and calprotectin concentrations, and diarrhoeal morbidity of Indonesian infants fed breast milk or probiotic/prebiotic-supplemented formula. J Paediatr Child Health 2013;49:1032-9.

17. Yap GC, Chee KK, Hong PY, Lay C, Satria CD, Sumadiono, et al. Evaluation of stool microbiota signatures in two cohorts of Asian (Singapore and Indonesia) newborns at risk of atopy. BMC Microbiol 2011;11:193.

18. Lewis SJ, Heaton KW. Stool form scale as a useful guide to intestinal transit time. Scand J Gastroenterol 1997;32:920-4.

19. Wang $Y$, Chen $H$. Use of percentiles and $Z$-scores in anthropometry. In: Preedy V, ed. Handbook of anthropometry : physical measures of human form in health and disease. New York: Springer, 2012:29-48.

20. Harmsen HJ, Wildeboer-Veloo AC, Raangs GC, Wagendorp AA, Klijn N, Bindels JG, et al. Analysis of intestinal flora development in breast-fed and formula-fed infants by using molecular identification and detection methods. J Pediatr Gastroenterol Nutr 
2000;30:61-7.

21. Knol J, Scholtens P, Kafka C, Steenbakkers J, Gro S, Helm K, et al. Colon microflora in infants fed formula with galacto- and fructo-oligosaccharides: more like breast-fed infants. J Pediatr Gastroenterol Nutr 2005;40:36-42.

22. Scholtens PA, Alles MS, Bindels JG, van der Linde EG, Tolboom JJ, Knol J. Bifidogenic effects of solid weaning foods with added prebiotic oligosaccharides: a randomised controlled clinical trial. J Pediatr Gastroenterol Nutr 2006;42:553-9.

23. Haarman M, Knol J. Quantitative real-time PCR assays to identify and quantify fecal Bifidobacterium species in infants receiving a prebiotic infant formula. Appl Environ Microbiol 2005;71:2318-24.

24. Cuello-Garcia CA, Fiocchi A, Pawankar R, YepesNuñez JJ, Morgano GP, Zhang Y, et al. World Allergy Organization-McMaster University Guidelines for Allergic Disease Prevention (GLAD-P): prebiotics. World Allergy Organ J 2016;9:10.

25. Boehm G, Jelinek J, Knol J, M'Rabet L, Stahl B, Vos P, et al. Prebiotics and immune responses. J Pediatr Gastroenterol Nutr 2004;39 Suppl 3:S772-3.

26. Bakker-Zierikzee AM, Alles MS, Knol J, Kok FJ, Tolboom JJ, Bindels JG. Effects of infant formula containing a mixture of galacto- and fructo-oligosaccharides or viable Bifidobacterium animalis on the intestinal microflora during the first 4 months of life.
Br J Nutr 2005;94:783-90.

27. Euler AR, Mitchell DK, Kline R, Pickering LK. Prebiotic effect of fructo-oligosaccharide supplemented term infant formula at two concentrations compared with unsupplemented formula and human milk. J Pediatr Gastroenterol Nutr 2005;40:157-64.

28. Nakamura N, Gaskins HR, Collier CT, Nava GM, Rai D, Petschow B, et al. Molecular ecological analysis of fecal bacterial populations from term infants fed formula supplemented with selected blends of prebiotics. Appl Environ Microbiol 2009;75:1121-8.

29. Kementerian Kesehatan Republik Indonesia. Data dan informasi: profil kesehatan Indonesia 2017 [Internet]. Jakarta: Kementerian Kesehatan Republik Indonesia; 2018 [cited 2018 Aug 16]. Available from: http:// www. depkes.go.id/resources/download/pusdatin/profil-kesehatan-indonesia/Data-dan-Informasi_Profil-KesehatanIndonesia-2017.pdf.

30. Tuohy KM, Finlay RK, Wynne AG, Gibson GR. A human volunteer study on the prebiotic effects of HP-inulinfaecal bacteria enumerated using fluorescent in situ hybridisation (FISH). Anaerobe 2001;7:113-8.

31. Harmsen HJM, Raangs GC, Franks AH, WildeboerVeloo ACM, Welling GW. The effect of the prebiotic inulin and the probiotic bifidobacterium longum on the fecal microflora of healthy volunteers measured by FISH and DGGE. Microb Ecol Health Dis 2002;14:211-20. 